|| Print ISSN: 2589-7837 || Online ISSN: 2581-3935 ||

International Journal of Medical Science and Diagnosis Research (IJMSDR)

Available Online at www.ijmsdr.com

NLM (National Library of Medicine ID: 101738824)

Original Research Article

Volume 5, Issue 10; October:2021; Page No. 15-27

\title{
CLINICAL DECISION MAKING ON DEEP CARIES MANAGEMENT IN THE ERA OF EVIDENCE BASED DENTISTRY IN INDIA- A SURVEY
}

P. Karunakar', M.S Ranga Reddy ${ }^{2}$, Umrana Faizuddin ${ }^{3}$, Basa Srinivas Karteek ${ }^{4}$, Chigurupati Swetha ${ }^{5}$, Kasturi Sri Ram ${ }^{6}$

${ }^{1}$ Professor and HOD, Department of Conservative Dentistry and Endodontics, Panineeya Institute of Dental Sciences and Research Centre, Hyderabad, Telangana, India

${ }^{2}$ Professor, Department of Conservative Dentistry and Endodontics, Panineeya Institute of Dental Sciences and Research Centre, Hyderabad, Telangana, India

${ }^{3}$ Professor, Department of Conservative Dentistry and Endodontics, Panineeya Institute of Dental Sciences and Research Centre, Hyderabad, Telangana, India

${ }^{4}$ Reader, Department of Conservative Dentistry and Endodontics, Panineeya Institute of Dental Sciences and Research Centre, Hyderabad, Telangana, India.

${ }^{5}$ Post Graduate student, Department of Conservative Dentistry and Endodontics, Panineeya Institute of Dental Sciences and Research Centre, Hyderabad, Telangana, India.

${ }^{6}$ Post Graduate student, Department of Conservative Dentistry and Endodontics, Panineeya Institute of Dental Sciences and Research Centre, Hyderabad, Telangana, India.

Conflicts of Interest: Nil

Corresponding author: Chigurupati Swetha

DOI: https://doi.org/10.32553/ijmsdr.v5i10.861

\section{Abstract:}

AIM: There is a global inconsistency in managing deep caries lesions and evidence-based strategies are not always followed. The aim of this study was to gain insight into current practices of Indian dentists for deep caries management.

MATERIALS AND METHOD: An invitation to participate in a web-based survey was sent to 600 randomly selected dentists. The respondents were queried about the routine approach to the diagnosis and treatment of deep carious lesions (DCLs).

RESULTS: Four hundred and twenty one (421) responses were obtained out of 600 survey forms with a response rate of $70.1 \%$. The majority of respondents $(89.7 \%)$ preferred total-caries excavation as treatment option in case of deep caries lesion (DCL) with reversible pulpitis. Only a small percentage (10\%) chose partial caries removal as an option, leaving some carious dentin close to the pulp to avoid pulp exposure. More than a half $(60.9 \%)$ of respondents considered that cariogenic microorganisms must be removed or caries would progress. Good clinical result was the most chosen reason $(80.3 \%)$ to choose a specific treatment. Patient's oral health $(86 \%)$ and patient's age $(69 \%)$ were the two patient-related factors most taken into account for the choice of treatment.

CONCLUSION: Total caries excavation is still the most frequently chosen treatment in teeth with DCL and reversible pulpitis. The collective assessment of the responses given by respondents allow to conclude that the new knowledge and concepts about caries lesions and the more conservative approach to DCLs have not yet been incorporated by Indian dentists into their clinical practice.

KEYWORDS: Deep carious lesions (DCLs), Total-Caries excavation, Treatment options, Survey 


\section{Introduction:}

Dental caries is one of the most widespread noncommunicable disease. It can be defined as a localized dysbiosis or disease, resulting from bacterial activity in the biofilm and characterized by a dissolution of the dental structure by acids formed from the fermentation of dietary carbohydrates, especially sucrose. ${ }^{(1,2)}$

The conventional treatment of caries is eradicating all infected biomass was deemed necessary prior to replacement of lost dental hard tissue with restorative materials.$^{3}$ This is a concern, particularly sin the case of deep carious lesions, where the risk of pulp exposure is an aggravating aspect for the maintenance of pulp vitality. Thus, avoiding the pulp exposure has a great impact on the prognosis regarding the longevity of affected teeth and reduces the cost of dental treatment. ${ }^{(4,5)}$ The suggested approaches for caries removal include Non-selective removal, formerly known as complete caries removal, which has high risk of pulp exposure, to selective caries removal, leaving soft dentin in the area of the cavity near the pulp. ${ }^{(6,7,8)}$

Treatment of cavitated deep carious lesions (DCLs) is part of routine daily practice for most of the dentists. In 2016, an international group published recommendations on terminology and evidence-based practice guidelines for the management of DCLs, these criteria considered complete excavation or removal of carious dentin over-treatment DCLs. $(9,10)$ Thus, the gradual or stepwise excavation and the selective caries removal are proposals, with scientific evidence, of ultraconservative treatment techniques for deep carious lesions. ${ }^{11}$

However, several surveys carried out in different countries indicate that some dentists to do overtreatment in the management of DCLs. There is limited information on the attitudes and behaviour of Indian dentists to deep caries lesions. Hence aim of this study was to conduct a survey investigating Indian dentist's knowledge, attitudes and factors regarding the conservative approach in management of deep caries lesions in teeth with reversible pulpitis.

\section{Materials and Methods}

An invitation to participate in online survey via Google Form with the corresponding link was sent via e-mail and online social platform (WhatsApp) to 600 dentists in India. The questionnaire consisted of multiple-choice questions and multiple selections with options for write-in answers where appropriate.

The questions were organized into three sections. The first section was to evaluate the demographic data of the respondents and focused on the technique and management approach used for deep caries lesion. The questions from the second section investigated the preferred treatment used for deep caries based on the perceived clinical simulation, while the third section of the questionnaire assessed the factors that affected the decision on deep caries management.

The data from the Google Form were analysed using absolute frequencies by utilizing IBM SPSS Statistics for windows, version 23. 


\section{Table 1: Questionnaire}

Thank you very much for taking the time to respond to this the survey about diagnostic and treatment strategies when you encounter a patient with deep carious lesion. This survey is completely anonymous and only takes about 5-7 minutes of your time.

1. Are you male or female?
a) Male
b) Female

2. Time since graduation completed?
a) <10years
b) >10years

3. In which of the following settings do you work?
a) Private practice
b) Academic
c) Public

4. How many years have you been practicing?
a) 1-5years
b) 6-10 years
c) 11-20 years
d) others

5. During the last 5 years have you attended any continuing education courses in the field of Cariology?
a) Yes
b) $\mathrm{No}$

6. During the past 5 years have you read any articles about Minimum Intervention (e.g., caries removal) in Cariology?
a) Yes
b) No 
7. Based on Case 1, what is the most likely diagnosis?
a) Healthy pulp
b) Reversible Pulpitis
c) Irreversible pulpitis
d) Pulp necrosis

7 i) Based on Case 1, what would be your indicated treatment:
a) Total caries excavation in 1 step
b) Total caries excavation in 2 steps
c) Partial caries excavation
d) Pulpotomy
e) Root canal treatment

8. Based on Case 2, what is the most likely diagnosis?
a) Healthy pulp
b) Reversible pulpitis
c) Irreversible pulpitis
d) Pulp necrosis

8i) Based on Case 2, what would be your indicated treatment
a) Total caries excavation in 1 step
b) Total caries excavation in 2 steps
c) Partial caries excavation
d) Pulpotomy
e) Root canal treatment

9. Based on Case 3, what is the most likely diagnosis?
a) Healthy pulp
b) Reversible pulpitis
c) Irreversible pulpitis
d) Pulp necrosis

9 b) Based on Case 3, what would be your indicated treatment
a) Total caries excavation in 1 step
b) Total caries excavation in 2 steps
c) Partial caries excavation
d) Pulpotomy
e) Root canal treatment 
10a) With reference to an asymptomatic vital tooth with a deep carious lesion on 20 years old female patient how would you proceed?

a) Perform total caries removal; if there is a small pulpal exposure, perform a direct pulp cap

b) Perform total caries removal; if there is a small pulpal exposure, perform root canal treatment

c) Perform caries removal in 2 steps (stepwise excavation); if there is a risk of pulp exposure, leave some carious dentin close to the pulp and then finish the caries removal a few weeks or months later

d) Perform partial caries removal; if there is a risk of pulp exposure, leave some carious dentin close to the pulp and perform a permanent restoration.

e) Other:

10b) If your answer to question 10 is "Perform caries removal in 2 steps (stepwise excavation); if there is a risk of pulp exposure, leave some carious dentin close to the pulp and then finish the caries removal a few weeks or months later

a) Then what time frame would you choose? Select one below:

b) 2 weeks to 3 months

c) After 3 to 6 months

d) More than 6 months

Then what filling material would you use between 2 appointments? Select one below:
a) Cavit
b) Glass Ionomer
c) Amalgam filling
d) Composite
e) IRM

11.What are the main reasons for choosing a particular treatment option for your patients with deep caries lesions?(Select all that apply)
a) Ease of use, familiarity with the technique
b) Good clinical results
c) Proven efficacy
d) Recommended by colleague
e) Recommended by clinical research
f) Recommended in text books
g) Profitability
h) Other:

12. What are the main factors upon which you base your treatment choice? (Select all that apply)
a) Patient's general health
b) Patient's age
c) Patient's oral health
d) Patient's attitude and preferences
e) Type of tooth (Anterior, Premolar, Molar) 
f) Further restoration needs of the tooth

g) Duration of the total treatment

13. How do you rate the following statements?

\begin{tabular}{|l|l|l|l|l|l|}
\hline & $\begin{array}{c}\text { Strongly } \\
\text { disagree }\end{array}$ & Disagree & No opinion & Agree & $\begin{array}{c}\text { Strongly } \\
\text { agree }\end{array}$ \\
\hline $\begin{array}{l}\text { Cariogenic microorganisms } \\
\text { must be removed or the } \\
\text { carious lesion will progress } \\
\text { under a restoration }\end{array}$ & & & & \\
\hline $\begin{array}{l}\text { A certain amount of } \\
\text { microorganisms can be left } \\
\text { under the restoration } \\
\text { because the carious lesion } \\
\text { will not progress if it is sealed }\end{array}$ & & & & & \\
\hline $\begin{array}{l}\text { The carious lesion must be } \\
\text { removed completely because } \\
\text { it presents a danger to the } \\
\text { vitality of the pulp. }\end{array}$ & & & & & \\
\hline $\begin{array}{l}\text { In the case of a deep carious } \\
\text { lesion, dental tissue close to } \\
\text { pulp must be preserved to } \\
\text { avoid any pulp exposure. }\end{array}$ & & & & & \\
\hline
\end{tabular}

\section{CASE -1}
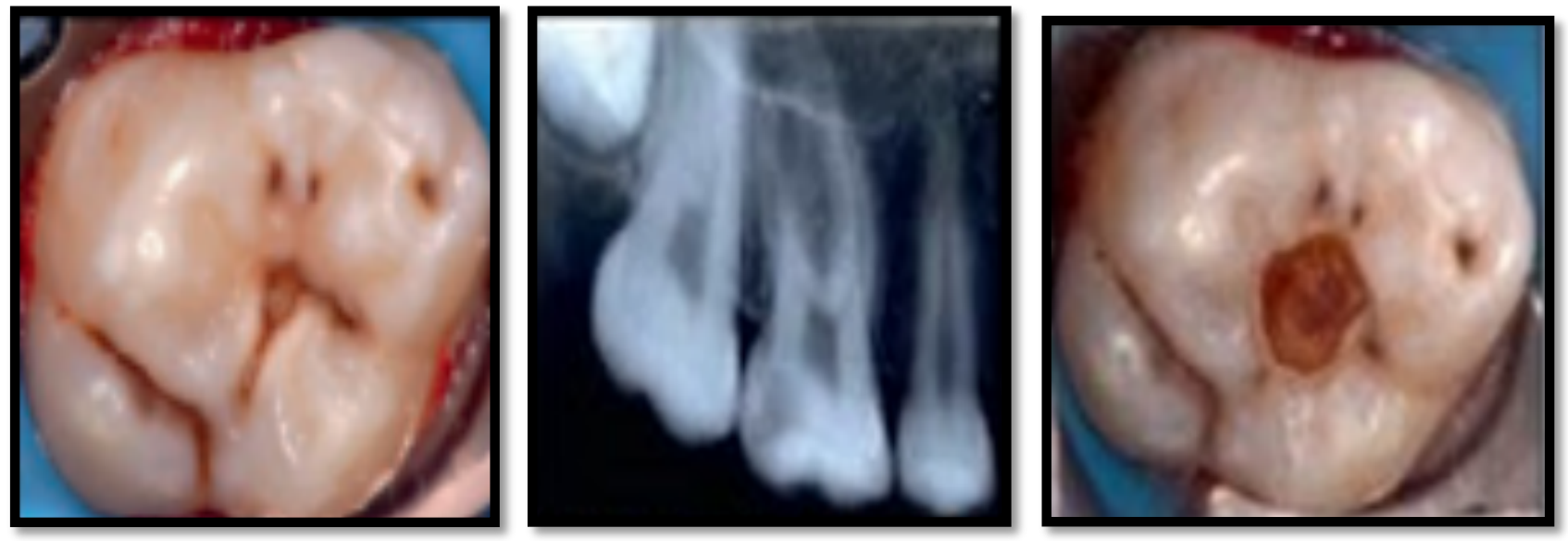


\begin{tabular}{|c|c|}
\hline Age & 25 year old female student \\
\hline General History & No significant medical history, no known allergies, oral contraception for 6 years \\
\hline Dental History & Extraction of the first left mandibular molar 3 years ago \\
\hline Oral Hygiene & Brushing teeth twice daily with fluoride toothpaste, no mouthwash, no dental floss \\
\hline $\begin{array}{l}\text { Reason for } \\
\text { Consultation }\end{array}$ & Sensitivity on upper right molar (pain while chewing and sensitivity to cold \\
\hline $\begin{array}{l}\text { Clinical and } \mathrm{X}- \\
\text { ray Examination }\end{array}$ & $\begin{array}{l}\text { Deep carious lesion reaching the inner half of dentin. Soft, yellowing carious } \\
\text { tissue in the center of the lesion, caries dentine moist and of yellowish color. } \\
\text { Positive thermal test of pulpal sensitivity (painful response to stimuli is not } \\
\text { prolonged after the test), negative vertical percussion test. No apical image on the } \\
\text { periapical radiograph. }\end{array}$ \\
\hline
\end{tabular}

\section{CASE- 2}
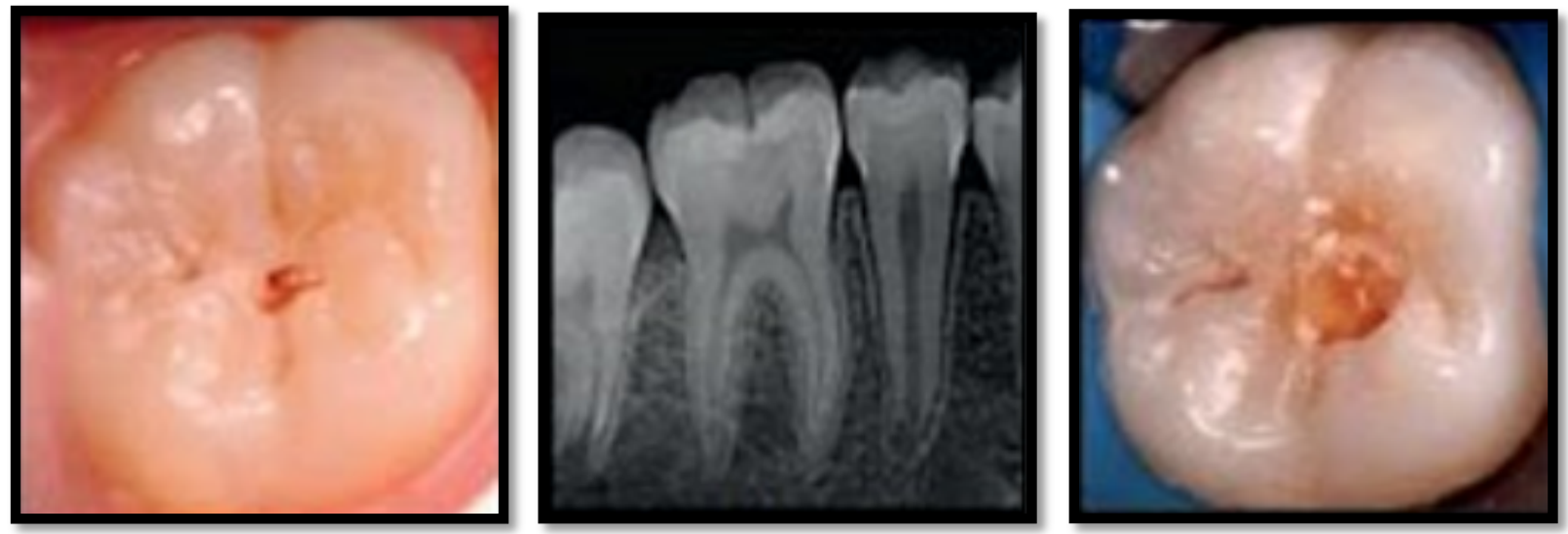

\begin{tabular}{|c|c|}
\hline Age & 11 year old female student \\
\hline General History & No significant medical history, no known allergies \\
\hline Dental History & $\begin{array}{l}\text { The patient lives with her mother and her } 5 \text { elder brothers and sisters, who benefit } \\
\text { from insurance; the patient has never been to the dentist before. }\end{array}$ \\
\hline Oral Hygiene & Brushing teeth twice daily with fluoride toothpaste, no mouthwash, no dental floss \\
\hline $\begin{array}{l}\text { Reason for } \\
\text { Consultation }\end{array}$ & Checkup in relation to a little sensitivity to cold on the lower right molar $\# 30$ \\
\hline $\begin{array}{l}\text { Clinical and } \mathrm{X}- \\
\text { ray Examination }\end{array}$ & $\begin{array}{l}\text { Deep carious lesion reaching the inner half of dentin with opaque sides which suggests } \\
\text { an active lesion. Soft carious tissue in the center of the lesion, caries dentin moist and } \\
\text { of yellowish color. Positive thermal test of pulpal sensitivity (painful response to } \\
\text { stimuli is not prolonged after the test); negative vertical percussion test. No apical } \\
\text { image on the periapical radiograph }\end{array}$ \\
\hline
\end{tabular}




\section{CASE-3}
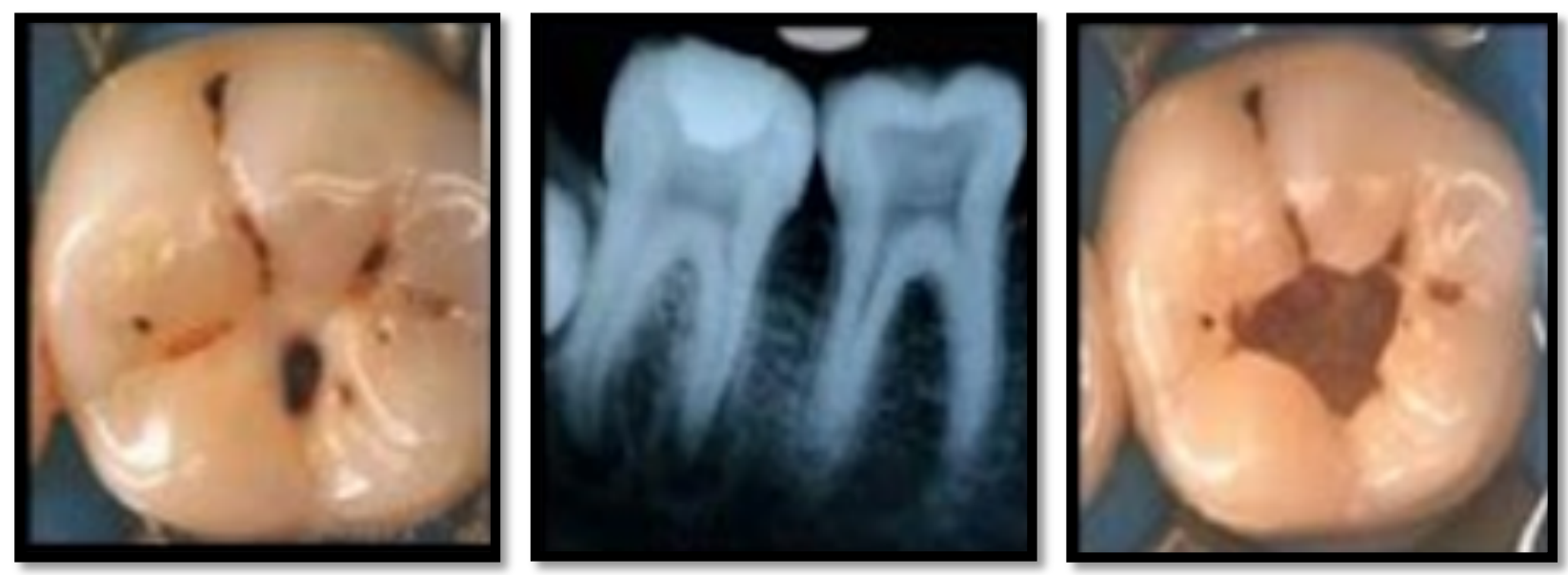

\begin{tabular}{|l|l|}
\hline Age & 14-year-old male high school student \\
\hline General History & No clinically significant medical history, no known allergies \\
\hline Dental History & Extraction of supernumerary tooth 1 year ago \\
\hline Oral Hygiene & $\begin{array}{l}\text { Brushing teeth 4 times a day with fluoride toothpaste, no } \\
\text { mouthwash, no dental floss }\end{array}$ \\
\hline Reason for Consultation & $\begin{array}{l}\text { Pain while chewing and sensitivity to sugar on mandibular right } \\
\text { no.30 }\end{array}$ \\
\hline Clinical and X-ray Examination & $\begin{array}{l}\text { Deep carious lesion reaching the internal one-half of dentin. Soft } \\
\text { caries tissue in the center of the lesion, caries dentin moist and dark } \\
\text { brown. Positive thermal test of pulpal sensitivity (painful response } \\
\text { to stimuli was not prolonged after the test); negative vertical } \\
\text { percussion test. No apical image on the radiograph }\end{array}$ \\
\hline
\end{tabular}

\section{RESULTS}

Four hundred and twenty one (421) responses were obtained out of 600 survey forms with a response rate of $70.1 \%$. Out of which ten (10) responses were excluded because they were answered incompletely. So, total of four hundred and elven (411) responses were taken into consideration. Among the respondents $278(67.6 \%)$ were males and $133(32.3 \%)$ were females. Of $268(65.2 \%)$ have a clinical experience of 6 to 10 years. 56.4\% had attended at least one continuing education course in cariology in the last 5 years. Two hundred and ninety two $(71 \%)$ had read an article about minimal intervention in the treatment of carious lesions. The answers to the 3 clinical cases are shown in figure 1 .

In case 1 reversible pulpitis was the most frequent pulpal diagnosis (90.1\%). Total caries excavation was selected as the best treatment option by $85.8 \%$ of dentists, being one-step total caries excavation the modality most frequently chosen (61\%). In case $2,63.8 \%$ of respondents agreed on a diagnosis of reversible pulpitis, and $28.5 \%$ considered that the pulp was healthy. Concerning the treatment, $89.7 \%$ selected total caries excavation as the best option, choosing one-step and two-step $74.1 \%$ and $15.6 \%$, respectively. 
In case $3,58.7 \%$ of dentists chose reversible pulpitis as the diagnosis, and $20.6 \%$ agreed on irreversible pulpitis as a possible diagnosis. Most of respondents $(61 \%)$ chose any of the types of total caries excavation, and less than a quarter of dentists $(22.4 \%)$ indicated that it would perform in this case root canal treatment. Very few dentists (less than 10\%) selected pulpotomy as a treatment option. Approximately $10 \%$ of respondents in each of the 3 cases chose partial caries excavation as treatment option, being this option significantly more chosen by dentists who received courses in cariology in the last 5 years.

Regarding the clinical situation raised in item 10 of questionnaire (an asymptomatic vital tooth with a DCL on 20 years old female patient), $75.2 \%$ of dentists chose to perform total caries removal and, if pulpal exposure occur, $52.6 \%$ and $22.6 \%$ would perform direct pulp capping or root canal treatment, respectively. Only Less than a fourth $(18.8 \%)$ chose to perform caries removal in 2 steps (stepwise excavation) and, if there is a risk of pulp exposure, leave some carious dentin close to the pulp, and then finish the caries removal a few weeks or months later. Only $6 \%$ of respondents chose to perform partial caries removal and, if there is a risk of pulp exposure, leave some carious dentin close to the pulp and perform a permanent restoration. This last option was again significantly more chosen by dentists who received courses in cariology in the last 5 years.
Four assertions were included in the questionnaire regarding knowledge and aptitude on the management of deep carious lesions for which the respondents had to indicate agreement or disagreement on a 5-point scale. When asked if cariogenic microorganisms must be removed or caries would progress, $60.9 \%$ strongly agreed, and only $10.4 \%$ and $8.6 \%$ disagreed or strongly disagreed, respectively. To the question if a certain amount of microorganisms could be left during caries removal, the answers were much divided, and only $15 \%$ and $12.6 \%$ agreed or strongly agreed, respectively.

When asked if a carious lesion must be removed to prevent its presence from damaging the vitality of the pulp, again the answers were very distributed, being the most frequent strongly agree $(30 \%)$. The fourth question asked if, treating a deep carious lesion, dental tissue close to the pulp must be preserved to avoid any pulp exposure, and again the opinions of the respondents were very variables, being "no opinion" the most frequent $(40.2 \%)$.

Lastly, dentists were asked about their reasons to choose specific treatment and about the factors influencing the treatment choice in managing deep carious lesions. The good clinical result was the most chosen reason $(80.3 \%)$, and patient's oral health $(86.0 \%)$ and patient's age $(69 \%)$ were the two patient-related factors most taken into account for the choice of treatment.

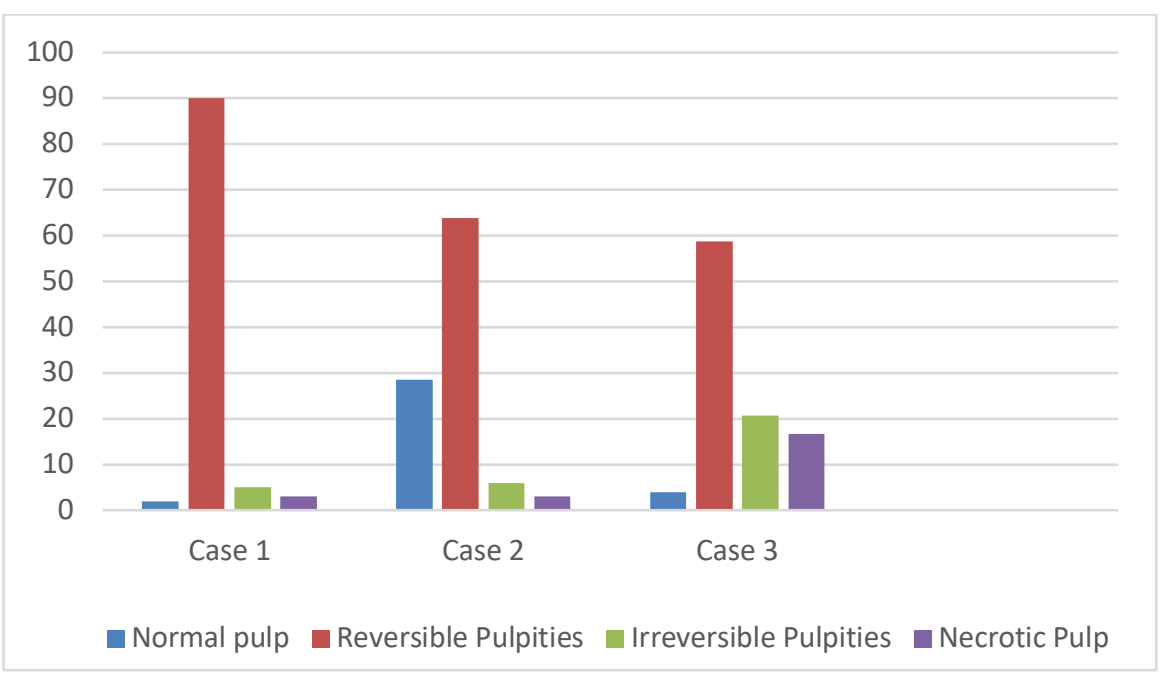




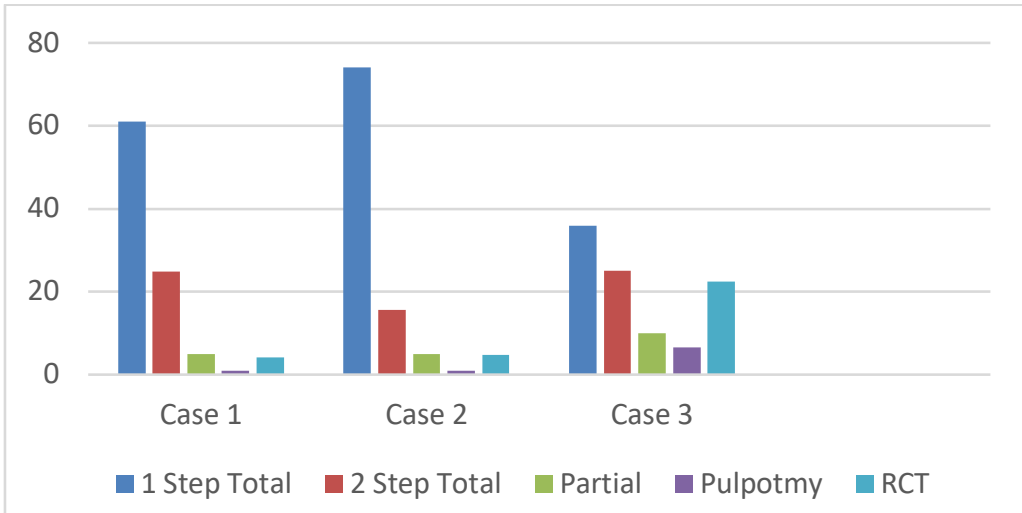

Fig 1: Pulpal diagnoses and treatment options selected by respondents for the 3 clinical case scenarios provided in the survey

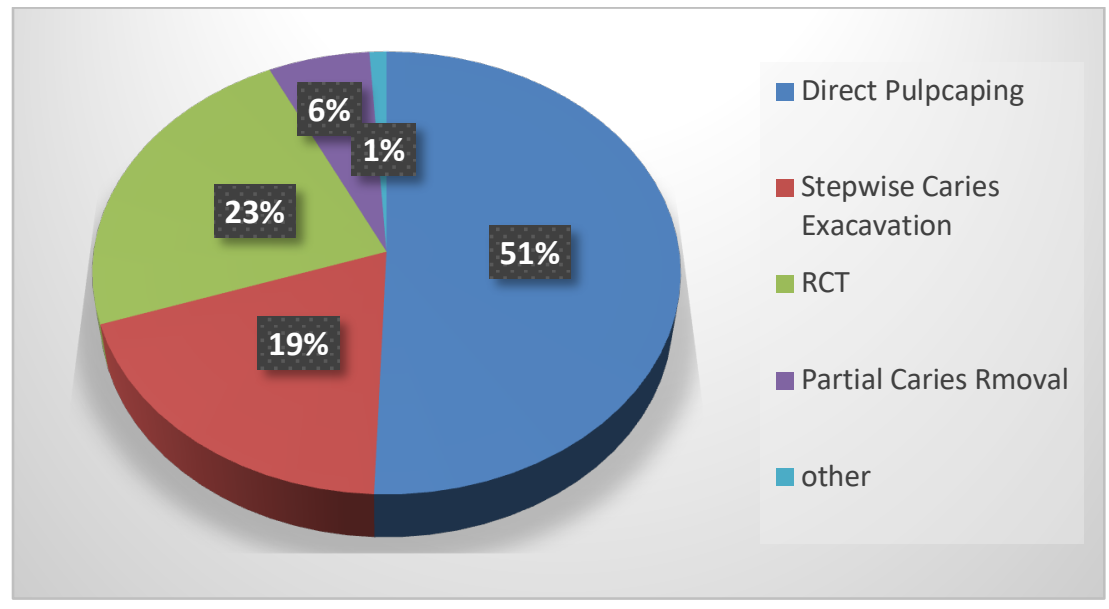

Fig 2: Treatment options selected by respondents for the case of an asymptomatic vital tooth with a DCL on 20 years old female patient. Direct pulp capping; RCT; Stepwise excavation; Partial caries removal.

\begin{tabular}{|l|l|l|l|l|l|}
\hline \multicolumn{2}{|c|}{ Table 2: Knowledge-related attitudinal responses to management of deep carious lesions. } \\
\hline Statement & \begin{tabular}{l} 
Responses (\%) \\
\cline { 2 - 6 } \\
Strongly \\
disagree
\end{tabular} & Disagree & $\begin{array}{l}\text { No } \\
\text { opinion }\end{array}$ & Agree & $\begin{array}{l}\text { Strongly } \\
\text { agree }\end{array}$ \\
\hline $\begin{array}{l}\text { Cariogenic microorganisms must be } \\
\text { removed or the carious lesion will progress } \\
\text { under a restoration. }\end{array}$ & 8.6 & 10.4 & 11.1 & 9 & 60.9 \\
\hline $\begin{array}{l}\text { A certain amount of microorganisms can be } \\
\text { left under the restoration because the carious } \\
\text { lesion will not progress if it is sealed. }\end{array}$ & 32.4 & 16.4 & 23.6 & 15 & 12.6 \\
\hline $\begin{array}{l}\text { The carious lesion must be removed } \\
\text { completely because it presents a danger to } \\
\text { the vitality of the pulp. }\end{array}$ & 14.5 & 17.2 & 20.8 & 17.5 & 30 \\
\hline $\begin{array}{l}\text { In the case of deep carious lesion, dental } \\
\text { tissue close to pulp must be preserved to } \\
\text { avoid any pulp exposure. }\end{array}$ & 13.7 & 11.5 & 40.2 & 10 & 24.6 \\
\hline
\end{tabular}




\section{Discussion}

This study was aimed to investigate dentists in India about their knowledge and decisions strategies in the management of DCLs. Four hundred and twenty one (421) responses were obtained out of 600 survey forms that were sent to dentists in India with a response rate of $70.1 \%$.

The respondents answered several questions related to the three clinical cases. The first and second clinical scenarios were asymptomatic patients with moderately DCLs not reaching the inner third of the dentin. The third case was a patient without symptoms with a deep DCL, with pulp testing suggestive of reversible pulpitis (i.e. no lingering pain to cold test). In all the three case scenarios respondents mostly diagnosed them as reversible pulpitis.

While choosing the treatment of deep carious lesions approaching the pulp tissue represents a particular challenge to the clinician because there is a high risk of accidental pulp exposure in this kind of lesion. In the present survey most opted approach is total caries excavation for more than $85 \%$ in cases 1 and 2 and $61 \%$ in case 3 . These percentages are in accordance with the surveys conducted by Koopaeei et al and Weber CM et al $(6,12)$ where the same clinical scenarios were used and the most preferred by most of the respondents was to remove all the carious tissue.

It was observed that dentists who received courses in cariology in the last 5 years were more likely to opt for a conservative treatment such as partial caries excavation, highlighting the importance of dental continuing education. Only $6 \%$ of the respondents in the present survey chose to perform partial caries removal and, if there is a risk of pulp exposure, leave some carious dentin close to the pulp and perform a permanent restoration.

The same can be seen in the case of the asymptomatic vital tooth with a deep carious lesion on 20 years old female patient (question no.10); again the dentists who had followed training in cariology in the last 5 years selected more frequently to perform partial caries removal. This finding agrees with the results of Koopaeei et al. ${ }^{13}$ who found that dentists stating more frequently reading articles and attending continuing education courses about minimally invasive treatments and cariology were more likely to be more conservative in their approach to management of DCLs.

The European Society of Endodontology (ESE) has recently published a position statement on management of deep caries and exposed pulp in which they have separated 'deep caries' and 'extremely deep carious lesions'. The earlier comprises extension of caries into the inner quarter of the dentine with a risk of pulp exposure during an operative procedure and the latter caries extending the entire thickness of dentine. The statement suggests that the pulp exposure is unavoidable in 'extremely deep' caries lesions during operative procedures. ${ }^{12}$

In the two firsts clinical scenarios, the carious lesions not reached the inner third of the dentin, with no risk of pulp exposure treatment of choice according to the ICCC group is selective removal to firm dentin. ${ }^{13}$ In the third case periapical radiograph showed that lesion reached the inner quarter of the dentin suggesting partial excavation, with selective removal to soft dentin, is the most appropriate treatment option for this type of DCLs. ${ }^{(7,13)}$ Studies have shown that direct complete excavation of deep carious lesions results in a rate of pulp exposure between 28.9 percent and 53 percent $^{(4,6,7)}$

In selective caries removal technique peripheral enamel and dentin must be removed until hard dentin is reached, ensuring a good seal and placement of the restoration, and soft carious dentin is left over the pulp, reducing the risk of pulp exposure. ${ }^{(6,13,14)}$ When caries was not removed completely, bacteria still present in the soft dentin are entombed and without access to nutrients, modifying the bacterial flora and stopping the advance of the caries, with rehardening the soft dentin. ${ }^{15}$ Bjorndal et al in his study concluded that carious lesions treated with selective removal to soft dentin showed deposition of tertiary dentin and increased radiopacity of the carious dentin left in the cavity floor ${ }^{16}$. 
A low proportion of professionals indicated stepwise excavation in the present study. In a study conducted by Parolo et al revealed that the necessity of a second appointment is a disadvantage to this procedure. Many patients do not return to receive the definitive restoration, which leads to the deterioration of the temporary filling and consequent caries progression. ${ }^{17}$

When asked about their knowledge, attitudes, and preferences, $60.9 \%$ strongly agreed that cariogenic micro-organisms must be removed or caries would progress. Only $20 \%$ agreed with the concept of leaving some carious tissues to preserve the vitality of the tooth. In a study by Weber et al. in Brazil, $8.8 \%$ of 54 dentist respondents would prefer partial caries removal for the management of DCLs ${ }^{18}$. In a German study by Schwendicke et al. ${ }^{19}$, dentists who believed residual caries was harmful tended to reject incomplete excavation of carious tissue, and those who felt it was acceptable favored indirect pulp-capping procedures. The authors found that $50 \%$ of dentists considered only complete caries excavation, even if pulp exposure was likely.

In the present study, the patient's health (48\%), age $(80 \%)$, attitude $(50 \%)$, and need for further restorations $(72 \%)$ were important factors in the treatment decision-making process. These results were in accordance with Koopaeei et al. ${ }^{6}$ However, in a study done by Stangvaltaite and colleagues', good results and easy procedure were the reasons most frequently chosen for the selection of a DCL treatment. Patient's age and patient's oral health were main patient-related factors among those who chose vital pulp therapy of carious exposures. ${ }^{20}$

\section{Conclusion}

On the basis of the results, most of the surveyed dentists still practiced complete carious tissue removal to hard dentin, relying on hardness as the most important criterion for excavation. Only a few dentists chose partial caries removal and a high percentage of them think that cariogenic microorganisms must be removed or caries would progress. It can be concluded that the new knowledge and concepts about caries lesions and the more conservative approach to DCLs have not yet been incorporated by most of the Indian dentists into their usual clinical practice. Although dental professionals have plenty access to scientific knowledge, this knowledge is not being translated into daily clinical practice.

\section{References}

1. Fejerskov O, Nyvad B, Kidd EAM. Dental Caries: The Disease and Its Clinical Management. 3rd Ed. Oxford (UK):Wiley Blackwell;2015.

2. Bjørnda L, Thylstrup A. A practice-based study on stepwise excavation of deep carious lesions in permanent teeth: a 1-year follow-up study. Community Dent Oral Epidemiol. 1998;26(2):122-8.

3. Kassebaum NJ, Smith AGC, Bernabe E, et al. Global, regional, and national prevalence, incidence, and disability-adjusted life years for oral conditions for 195 countries, 1990-2015: a systematic analysis for the global burden of diseases, injuries, and risk factors. J Dent Res 2017;96:380-387.

4. Whitworth JM, Myers PM, Smith J , Paredes AW, McCabe JF. Endodontic complications after plastic restorations in general practice. Int Endod J. 2005;38(6):409-16.

5. Bjørndal L, Claes R, Gitte B, Merete M, Marianne K, Peggy N et al. Treatment of deep caries lesions in adults: randomized clinical trials comparing stepwise vs. direct complete excavation, and direct pulp capping vs. partial pulpotomy. Eur J Oral Sci. 2010;118(3):290-7.

6. Koopaeei MM, Inglehart MR, McDonald N, Fontana M. General dentists', pediatric dentists', and endodontists' diagnostic assessment and treatment strategies for deep carious lesions. A comparative analysis. J Am Dent Assoc. 2017;148:64-74.

7. Carvalho JC, Dige I, Machiulskiene V, Qvist V, Bakhshandeh A, Fatturi-Parolo C, Maltz M. Occlusal Caries: biological approach for its diagnosis and management. Caries Res. 2016;50:527-42.

8. Banerjee A, Frencken JE, Schwendicke F, Innes NPT. Contemporary operative caries management: consensus recommendations on minimally invasive caries removal. Br Dent J 2017;223:215-222. 
9. Schwendicke F. Contemporary concepts in carious tissue removal: a review. J Esthet Restor Dent. 2017;29:403-8.

10. Segura-Egea JJ. Complete excavation or removal of carious tissues to hard dentin: Overtreatment. J Oral Res. 2017;6:30-1.

11. Jardim JJ, Simoneti DNM, Maltz M. Partial caries removal in permanent teeth: six-year follow-up. RFO UPF. 2001;(20):1.

12. Duncan HF, Galler KM, Tomson PL, et al. European Society of Endodontology position statement: management of deep caries and the exposed pulp. Int Endod J 2019;52:923-934.

13. Schwendicke F, Frencken JE, Bjorndal L, et al. Managing carious lesions: consensus recommendations on carious tissue removal. Adv Dent Res 2016;28:58-67.

14. Ricketts D, Lamont T, Innes NP, Kidd E, Clarkson JE. Operative caries management in adults and children. Cochrane database of systematic reviews. 2013(3).

15. Maltz M, Alves LS, Jardim JJ, dos Santos Moura M, de Oliveira EF. Incomplete caries removal in deep lesions: a 10-year prospective study. American journal of dentistry. 2011 Aug;24(4):211-4.
16. Bjørndal L, Larsen T, Thylstrup A. A clinical and microbiological study of deep carious lesions during stepwise excavation using long treatment intervals. Caries research. 1997;31(6):411-7.

17. Parolo CCF, Heller D, Bitello LF, Podestá K, Souza DCC, Hashizume LN, Maltz M. Effectiveness of the stepwise excavation treatment performed by dental students in Porto Alegre, Brazil. Caries Res. 2007;41:269. Abstr. 5.

18. Weber CM, Alves LS, Maltz M. Treatment decision for deep caries lesions in the public health service in Southern Brazil. J Public Health Dent. 2011;71:265-70.

19. Schwendicke F, Meyer-Lueckel H, Dörfer C, Paris S. Attitudes and behaviour regarding deep dentin caries removal: a survey among German dentists. Caries research. 2013;47(6):566-73.

20. Stangvaltaite L, Kundzina R, Eriksen HM, Kerosuo E. Treatment preferences of deep carious lesions in mature teeth: questionnaire study among dentists in Northern Norway. Acta Odontol Scand. 2013;71:1532-7. 